\title{
Experimental study on the through-thickness properties of structural steel thick plate and its heat-affected zone at low temperatures
}

\author{
Yuan-qing $\mathrm{WANG}^{\dagger}$, Xiao-wei LIAO, Yuan-yuan ZHANG, Yong-jiu SHI \\ (Key laboratory of Civil Engineering Safety and Durability of China Education Ministry, Department of Civil Engineering, \\ Tsinghua University, Beijing 100084, China) \\ †E-mail: wang-yq@mail.tsinghua.edu.cn
}

Received Sept. 13, 2014; Revision accepted Jan. 27, 2015; Crosschecked Feb. 26, 2015

\begin{abstract}
Lamellar tearing and crack-induced brittle failures along steel plates in the through-thickness direction seriously threaten the safety and reliability of steel thick plate structures in construction and service, especially at low ambient temperatures. Three kinds of tests, including uniaxial tensile tests, Charpy V-Notch impact tests, and three-point bending (TPB) tests were performed at normal and low temperatures to investigate the through-thickness mechanical properties, impact and fracture toughness of Q345B structural steel plates with thicknesses from 60 to $165 \mathrm{~mm}$. The test specimens were mainly sampled along the through-thickness direction of the plate, but transverse specimens along the rolling direction were also involved. The ductility index (percentage reduction of area), impact toughness index (Charpy impact energy), and fracture toughness index (critical crack tip opening displacement (CTOD) values) all decrease as the temperature declines. All the mechanical properties and the impact and fracture toughness along the through-thickness direction are worse than those along the rolling direction. The results also offer experimental support for the determination of an evaluation indicator for structural steel thick plates with through-thickness characteristics.
\end{abstract}

Key words: Structural steel thick plate, Through-thickness properties, Mechanical properties, Impact toughness, Fracture toughness, Low temperature doi:10.1631/jzus.A1400273

Document code: A

CLC number: TU391

\section{Introduction}

With the development of smelting and construction technology, structural steel thick plates have been widely employed in long-span steel bridges, super-high rise buildings, and other newly-emerging large-scale steel structures in recent years (Chai, 2004; Chen, 2007). However, due to insufficient recognition of the mechanical properties of steel thick

\footnotetext{
* Project supported by the National Natural Science Foundation of China (Nos. 51378289 and 51178244), and the Specialized Research Fund for the Doctoral Program of Higher Education of China (No. 20130002110085)

(D) ORCID: Yuan-qing WANG, http://orcid.org/0000-0003-14701177

(C) Zhejiang University and Springer-Verlag Berlin Heidelberg 2015
}

plates, some crack-induced through-thickness failures and lamellar tearing failures have been discovered during the processes of welding and construction of steel structure thick plates (Wang et al., 2010).

Several adverse factors may contribute to through-thickness failure of steel thick plates. First, the through-thickness properties of a thick plate are significantly different from the transverse properties within the rolling plane since the process of smelting and rolling reduces both through-thickness toughness and ductility (Zhao et al., 2010). Non-metallic inclusions inside the steel material will cause the thick plate to become layered, and center segregation especially will generate an obvious deterioration of through-thickness properties. Also, during the welding process, the large quantity of welding heat input 
will pose a greatly adverse effect on the crackresistance ability and toughness of the parent metal adjacent to the weld. Besides, a variety of studies have demonstrated that steel structures are more likely to be subjected to brittle fracture while serviced and constructed at low temperatures (Wu et al., 2004; Wang et al., 2007), especially in the case of welding engineering using steel thick plates. Nevertheless, Chinese codes (CISA, 2006; 2009a; 2011) just stipulate the requirements of the percentage reduction of area in the through-thickness tensile test in order to satisfy the through-thickness properties. Therefore, it is of great significance to experimentally investigate the through-thickness mechanical properties of steel thick plate so as to guarantee its structural safety and reliability.

A few investigations have been devoted to investigating the through-thickness properties of steel thick plates. Barsom and Korvink (1998) investigated the through-thickness properties of structural steel plates and structural shape steel products. Kuwamura et al. (2003) showed that as the plate thickness increases, the stress state in the defects of structural members is transferred from plane stress to plane strain, which raises the tendency of suffering brittle fracture in structural members. Zhang (2006) obtained the relationship between sulfur content and the percentage reduction of area by through-thickness tensile tests of $14 \mathrm{MnNbq}$ steel plate. Gao et al. (2008) performed impact toughness experiments on the weld and on parental metal adjacent to the weld and fusion line of Q460 steel plates $(100 \mathrm{~mm}, 110 \mathrm{~mm})$ at $-40{ }^{\circ} \mathrm{C}$, which had been used in the China National Stadium. Wang et al. (2013) experimentally studied the mechanical properties and fracture toughness of steel thick plates at different positions along the thickness direction. However, the above-mentioned studies are not systematic enough to meet the requirements for structural thick plates with through-thickness characteristics as applied in practical engineering.

In this paper, three kinds of experiments have been conducted to systematically study the throughthickness mechanical properties: uniaxial tensile tests, Charpy impact tests, and three-point bending (TPB) tests of structural steel thick plate and its heat affect zone (HAZ). The effects of different plate thicknesses, weld sizes, and ambient temperatures have also been taken into consideration, so as to pro- vide a technical basis for the assessment of the through-thickness properties of thick plate steel.

\section{Experimental}

A series of tests for $60 \mathrm{~mm}$ thick structural steel plates of Q345B at low temperatures $(20,0,-20,-40$, and $-60{ }^{\circ} \mathrm{C}$ ) were carried out in this paper, and the other four different thick plates (i.e., $80,100,120$, and $165 \mathrm{~mm}$ ) were included at $20^{\circ} \mathrm{C}$ as well. The basic mechanical property indices, such as yield strength $R_{\mathrm{el}}$, ultimate tensile strength $R_{\mathrm{m}}$, and percentage reduction of area $\Psi$, were obtained by uniaxial tensile tests. The Charpy impact energy $A_{\mathrm{k}}$ and critical crack tip opening displacement (CTOD) values $\delta_{\mathrm{m}}$ were determined by Charpy V-Notch impact tests and TPB tests, respectively. The fractured surfaces of test specimens in Charpy impact tests and TPB tests were scanned by an electron microscope to study the micro-structures of structural thick plate with through-thickness characteristics.

\subsection{Specimen materials}

In this experiment, the Wuyang Iron and Steel Co. Ltd. in China helped by offering structural steel thick plates of Q345B, and the welding processes was accomplished by the China 22MCC Group Co. Ltd. The welding details of the welds are shown in Table 1.

Table 1 Welding process parameters

\begin{tabular}{lc}
\hline \multicolumn{1}{c}{ Item } & Description \\
\hline Welding position & Flat position welding \\
Welding method & Gas shielded arc welding \\
Welding wire & ER50-6 \\
Diameter of welding wire (mm) & 1.2 \\
Shielding gas & $\mathrm{CO}_{2}$ \\
Current (A) & $250-300$ \\
Voltage (V) & $28-32$ \\
Velocity (cm/min) & $30-35$ \\
\hline
\end{tabular}

\subsection{Experimental setup}

The tensile tests and TPB tests were performed with an electronic universal testing machine (INSTRON), as shown in Fig. 1a, and the initial strain rate for the tensile test and the vertical deformation rate for the bending test were $0.00067 \mathrm{~s}^{-1}$ and $30 \mathrm{~mm} / \mathrm{min}$, respectively. Both the tensile and TPB specimens were cooled by the mixed steam of liquid nitrogen and air in a sealed attemperator instrumented with INSTRON; the lowest temperature can be close to $-70{ }^{\circ} \mathrm{C}$. The testing arrangements of the uniaxial 
tensile tests and the TPB tests inside the attemperator are illustrated in Figs. $1 \mathrm{~b}$ and 1c. As shown in Fig. 1d, the Charpy impact tests were implemented by a pendulum impact testing machine (SANS) with a standardized initial energy of $300 \mathrm{~J}$. A mixture of liquid nitrogen and alcohol was employed to refrigerate the Charpy impact specimens, and the temperature could approach $-80{ }^{\circ} \mathrm{C}$. The temperature in the impact test is measured by employing a special thermometer, with range -80 to $50{ }^{\circ} \mathrm{C}$.

(a)

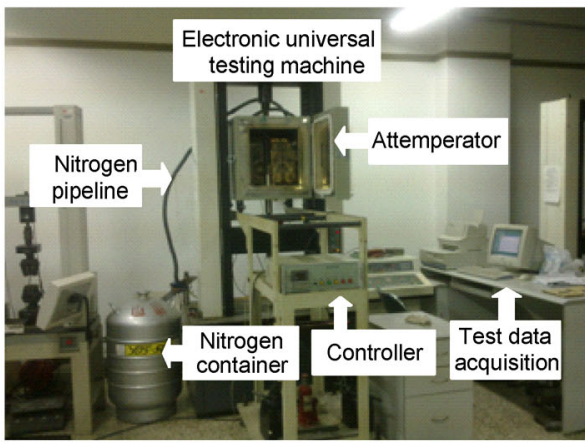

(c)

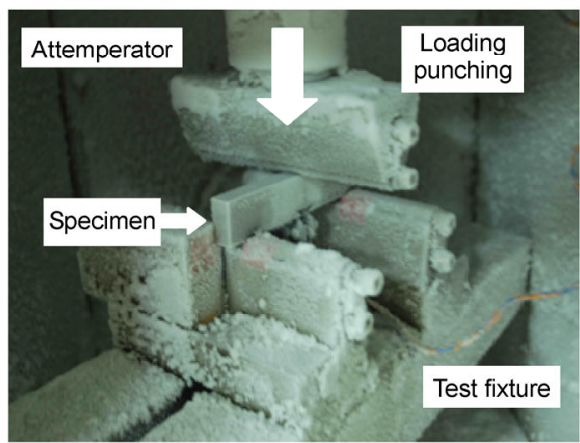

\section{Uniaxial tensile tests}

\subsection{Tensile test specimens}

Three categories of tensile test specimens were sampled from base metal and its HAZ influenced by the cross type butt weld, respectively (Fig. 2). The specimens were fabricated according to the standards GB/T 228-2002 (SBMI, 2002) and GB/T 13239-2006 (CISA, 2007).

Through-thickness specimens from the base

(b)

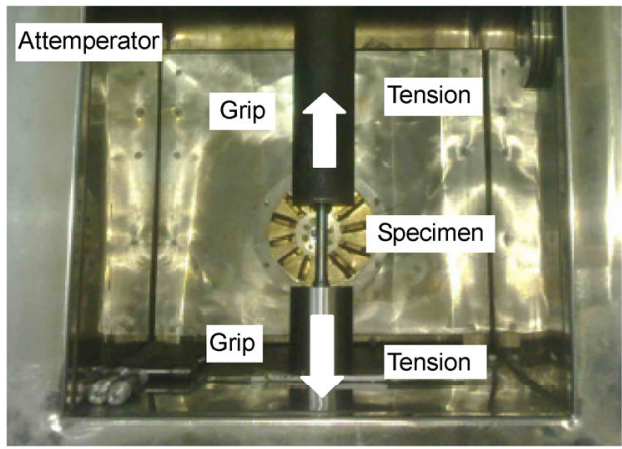

(d)

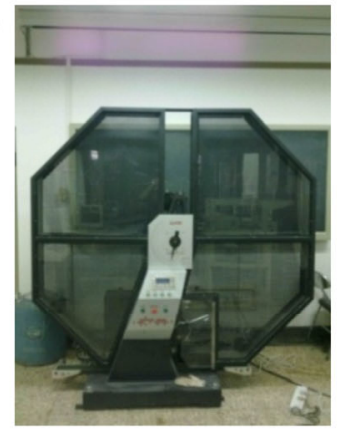

Fig. 1 Experimental equipment for uniaxial tensile and TPB tests (a); Tensile test scene in attemperator (b); TPB test scene in attemperator (c); Experimental equipment for Charpy impact tests (d)

(a)

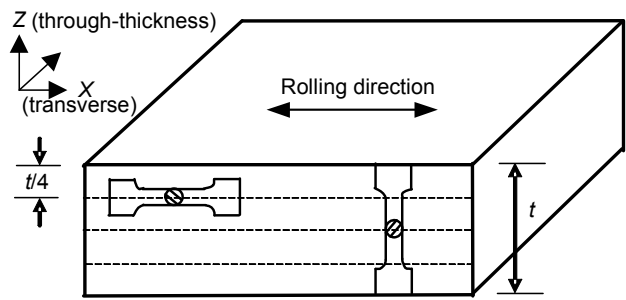

(c)

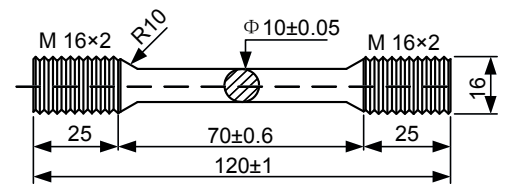

(b)

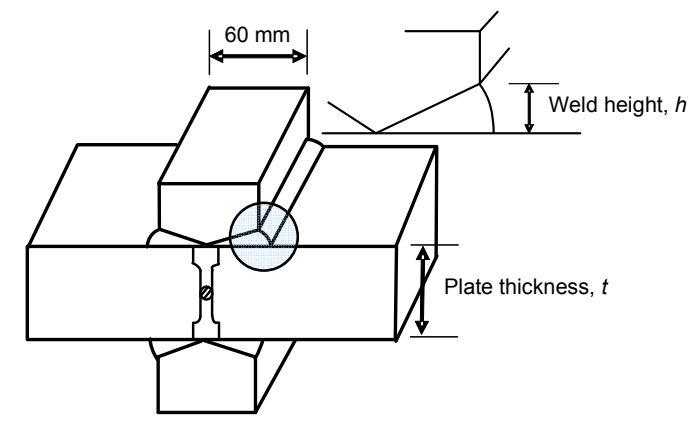

(d)

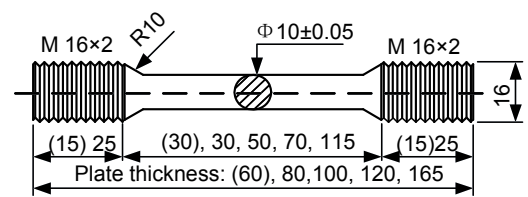

Fig. 2 Sampling location and physical dimension of the tensile test specimen (unit: $\mathbf{m m})$ : (a) base metal specimen $(t=60,80$, 100, 120, 165); (b) HAZ specimen $(h=21,30,39,48)$; (c) transverse specimen; (d) through-thickness specimen 
metal are shown in Fig. 2a. In order to make a comparison of the transverse and through-thickness properties, the transverse specimens, which are parallel to the rolling direction, were also sampled from the thick plate at one fourth of the plate thickness. Through-thickness specimens sampled from HAZ of the cross type butt weld with four different weld sizes $(h=21,30,39,48 \mathrm{~mm})$ are shown in Fig. $2 \mathrm{~b}$, so as to study the effects of different welding heat inputs.
Table 2 offers the groupings of tensile test specimens, and three replicated tensile specimens were produced for each condition point, and average values of the test results were adopted.

\subsection{Experimental results and discussion}

Detailed research was devoted to the plate with the thickness $60 \mathrm{~mm}$, and the test results shown in Fig. 3 take the sampling location and temperature as

Table 2 Groupings of test specimens

\begin{tabular}{|c|c|c|c|c|}
\hline \multirow{2}{*}{ Test type } & \multirow{2}{*}{ Specimen } & \multirow{2}{*}{$\begin{array}{c}\text { Sampling location and } \\
\text { type }\end{array}$} & \multicolumn{2}{|c|}{ Temperature points $\left({ }^{\circ} \mathrm{C}\right)$} \\
\hline & & & $60 \mathrm{~mm}$ & $80,100,120,165 \mathrm{~mm}$ \\
\hline \multirow[t]{6}{*}{ Tensile } & Base material & $X$-direction & & \\
\hline & & $Z$-direction & & \\
\hline & HAZ & $Z$-T1 $(h=21 \mathrm{~mm})$ & & \\
\hline & & $Z$-T2 $(h=30 \mathrm{~mm})$ & $20,0,-20,-40,-60^{\circ} \mathrm{C}$ & $20{ }^{\circ} \mathrm{C}$ \\
\hline & & $Z$-T3 $(h=39 \mathrm{~mm})$ & & \\
\hline & & $Z$-T4 $(h=48 \mathrm{~mm})$ & & \\
\hline \multirow[t]{3}{*}{ Impact } & Base material & $X$-direction & & \\
\hline & & $Z$-direction & $20,0,-20,-40,-60^{\circ} \mathrm{C}$ & $20{ }^{\circ} \mathrm{C}$ \\
\hline & HAZ & Z-T1 & & \\
\hline \multirow[t]{4}{*}{ TPB } & Base material & $X$-direction & $20,0,-20,-40,-60^{\circ} \mathrm{C}$ & $20{ }^{\circ} \mathrm{C}$ \\
\hline & & $Z$-direction & - & $20^{\circ} \mathrm{C}^{*}$ \\
\hline & HAZ & Z-T1 & $20,0,-20,-40,-60^{\circ} \mathrm{C}$ & $20^{\circ} \mathrm{C}$ \\
\hline & & Z-T2, Z-T3, Z-T4 & $20^{\circ} \mathrm{C}$ & - \\
\hline
\end{tabular}

* Only test specimens with plate thickness of 120 and $165 \mathrm{~mm}$ were tested at $20{ }^{\circ} \mathrm{C}$

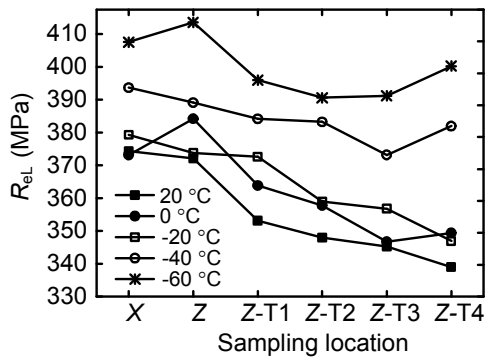

(a)

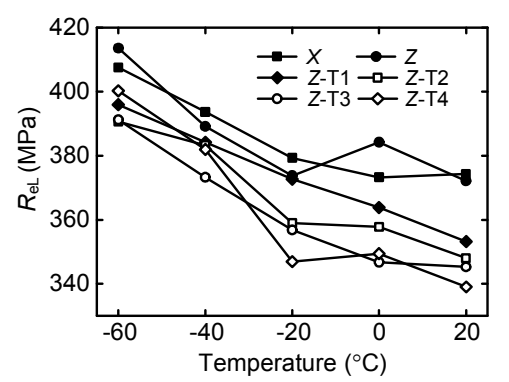

(d)

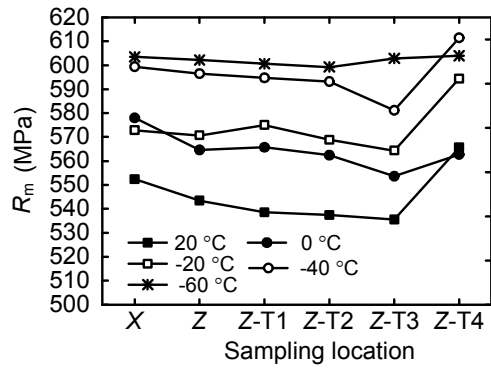

(b)

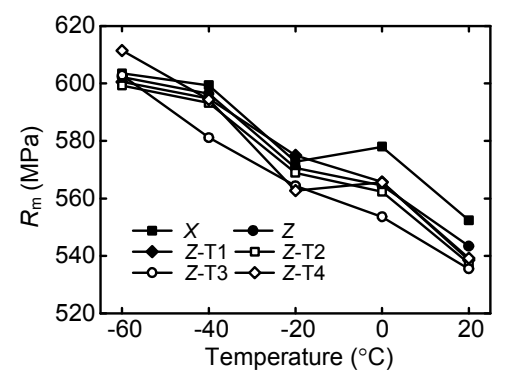

(e)

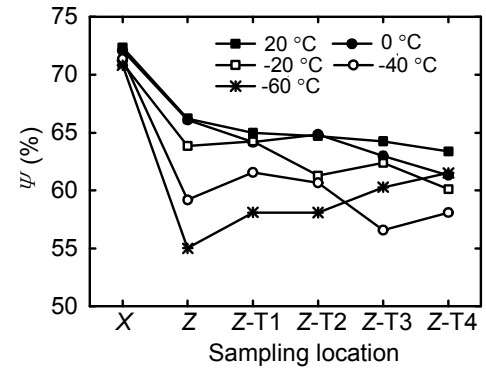

(c)

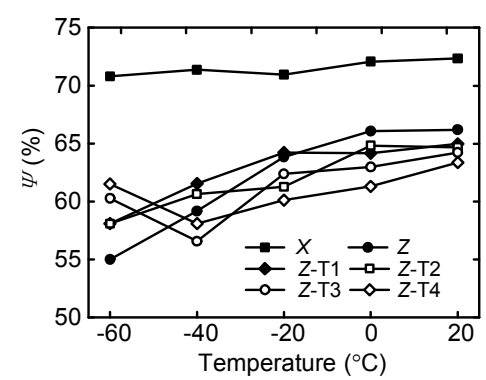

(f)

Fig. 3 Mechanical properties versus sampling location (a)-(c) and temperature (d)-(f) for the $60 \mathrm{~mm}$ plate (a) and (d) Yield strength; (b) and (e) Ultimate tensile strength; (c) and (f) Percentage reduction of area 
abscissa, respectively. From Figs. 3a-3c, as the weld size increases, the through-thickness yield strength $R_{\mathrm{el}}$ experiences an obvious drop, especially at the temperature points 20,0 , and $-20{ }^{\circ} \mathrm{C}$, and the through-thickness ultimate tensile strength $R_{\mathrm{m}}$ and ductility index $\Psi$ values decrease slightly. As shown in Figs. 3d-3f, it can be seen that, with the decrease of temperature, the strength indices $R_{\mathrm{el}}$ and $R_{\mathrm{m}}$ of various locations all increase, and the ductility index $\Psi$ value falls. Additionally, the strength indices and ductility index along the through-thickness direction are generally inferior to these indices along the transverse direction. The lower through-thickness $\Psi$ values than transverse $\Psi$ values in Fig. 3 confirm the deteriorated lamellar-tearing resistance ability of steel thick plates along the through-thickness direction.

The mechanical properties versus different plate thicknesses at $20{ }^{\circ} \mathrm{C}$ are shown in Fig. 4. As mentioned above, the indices of mechanical properties along the through-thickness direction are usually inferior to these along transverse direction. As the plate thickness increases, the strength indices $R_{\mathrm{el}}$ and $R_{\mathrm{m}}$, and ductility index $\Psi$ values all decrease. Especially for plates from 100 to $165 \mathrm{~mm}$, these throughthickness mechanical properties undergo a drastic drop, while the through-thickness $R_{\mathrm{el}}$ and $\Psi$ of the plates of 60 to $80 \mathrm{~mm}$ decrease relatively smoothly. Noticeably, the reduction of ultimate tensile strength $R_{\mathrm{m}}$ and ductility index $\Psi$ along the transverse direction are less than that along the through-thickness direction with the increase of plate thickness. Although the experimental results show some dispersion, it can be seen that the unfavorable influence of welding heat input reduces the through-thickness mechanical and ductility indices.
Theoretical and experimental studies demonstrated that, at the temperature ranging from -70 to $20{ }^{\circ} \mathrm{C}$, the following Eqs. (1) and (2) can effectively express the variations of yield and ultimate strength with temperature (Wu et al., 2004):

$$
\begin{aligned}
& R_{\mathrm{eL}}(T)=R_{\mathrm{eL}}\left(T^{\prime}\right) \exp \left[q_{\mathrm{y}}\left(T^{\prime}-T\right)\right], \\
& R_{\mathrm{m}}(T)=R_{\mathrm{m}}\left(T^{\prime}\right) \exp \left[q_{\mathrm{u}}\left(T^{\prime}-T\right)\right],
\end{aligned}
$$

where $R_{\mathrm{el}}(T), R_{\mathrm{el}}\left(T^{\prime}\right)$ and $R_{\mathrm{m}}(T), R_{\mathrm{m}}\left(T^{\prime}\right)$ are the yield and ultimate tensile strength at temperatures $T$ and $T^{\prime}$, respectively; and $q_{\mathrm{y}}$ and $q_{\mathrm{u}}$ are the temperature sensitive factors of yield and ultimate tensile strength, respectively.

As shown in Fig. 5, the empirical relationships of yield strength or ultimate tensile strength along the transverse and through-thickness directions of the $60 \mathrm{~mm}$ plate were achieved by experimental data fitting using Origin with Eqs. (1) and (2), where the reference temperature point $T^{\prime}$ is $20^{\circ} \mathrm{C}$. Although the test data exhibits some scatter, it still shows that the $R_{\mathrm{el}}(T)$ and $R_{\mathrm{m}}(T)$ of specimens from base material and its HAZ all increase as temperature decreases.

\section{Charpy V-Notch impact tests}

\subsection{Charpy V-Notch impact test specimens}

The Charpy impact energy $A_{\mathrm{k}}$ is one of the basic properties of material toughness, and is widely used as an evaluation index of material toughness in engineering applications (Ren et al., 2009; Wang et al.,

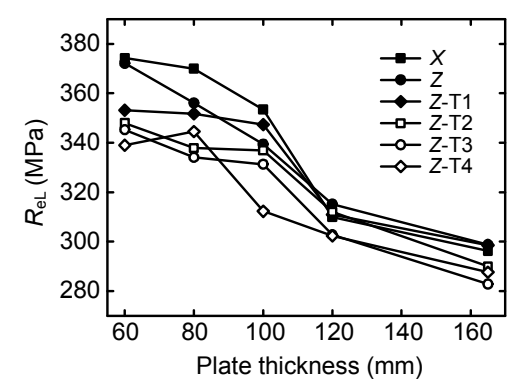

(a)

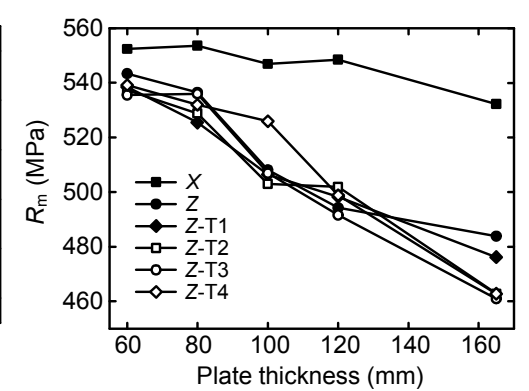

(b)

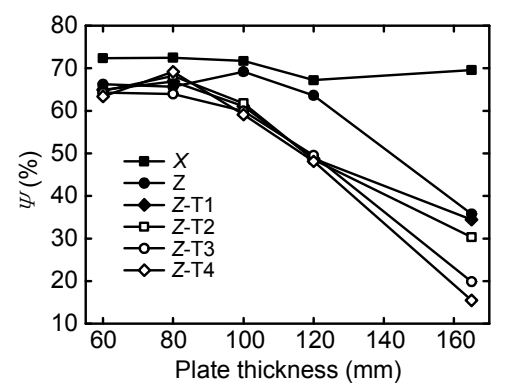

(c)

Fig. 4 Mechanical properties versus plate thickness at $20{ }^{\circ} \mathrm{C}$

(a) Yield strength; (b) Ultimate tensile strength; (c) Percentage reduction of area 


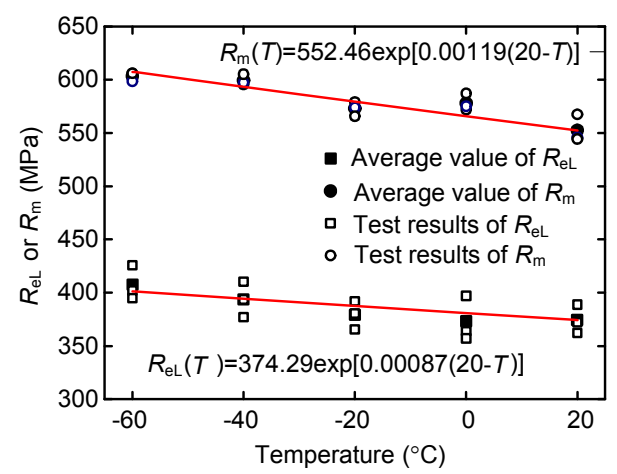

(a)

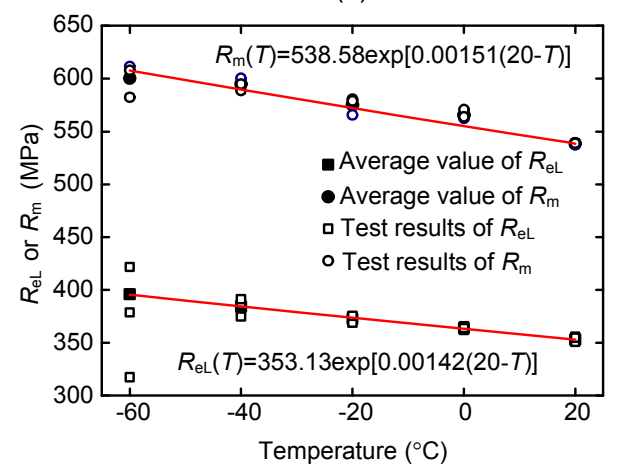

(c)

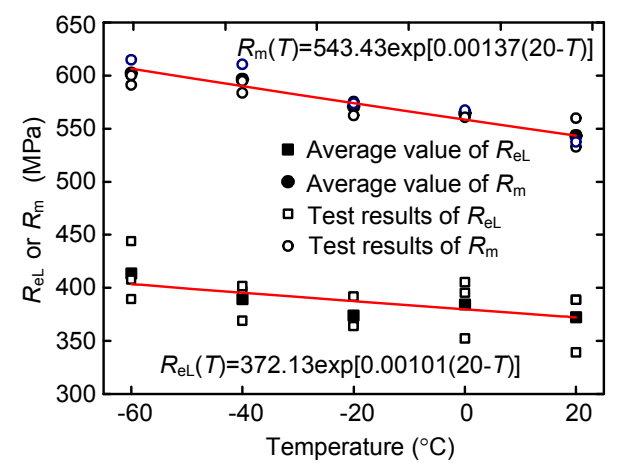

(b)

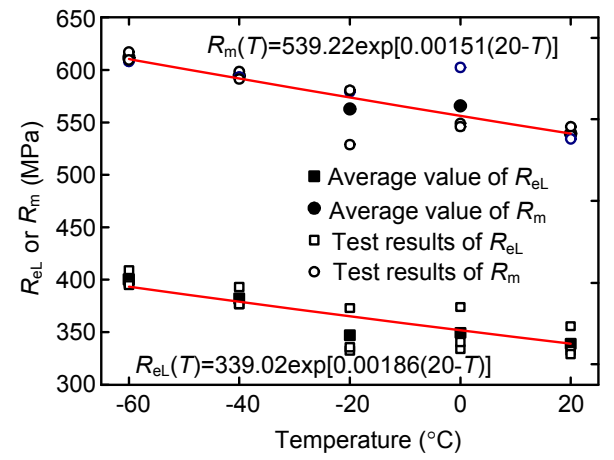

(d)

Fig. 5 Yield and ultimate tensile strength versus temperature (T) for the $60 \mathrm{~mm}$ plate: (a) transverse specimen from base metal (X); (b) through-thickness specimen from base metal (Z); (c) specimen from HAZ (Z-T1, $h=21 \mathrm{~mm})$; (d) specimen from HAZ $(Z-T 4, h=48 \mathrm{~mm})$

2012) because of the simplicity and convenience of the impact test. Three categories of Charpy V-Notch impact test specimens were machined (Fig. 6), including transverse specimens, through-thickness specimens from the base metal, and throughthickness specimens from HAZ of the cross type butt weld. The geometries and physical dimensions of the impact test specimen illustrated in Fig. 6c were in accordance with the standard GB/T 229-2007 (CISA, 2008a). The groupings of the Charpy impact specimens are shown in Table 2; four replicated impact specimens were employed for each condition point.

\subsection{Experimental results and discussion}

The impact tests for the $60 \mathrm{~mm}$ thick plate were performed at five temperature points $(20,0,-20,-40$, and $-60{ }^{\circ} \mathrm{C}$ ), and the other four different thickness plates $(t=80,100,120$, and $165 \mathrm{~mm})$ were incorporated into this test at $20^{\circ} \mathrm{C}$ as well. The average $A_{\mathrm{k}}$ values of the four tested specimens are shown in Fig. 7.

The curves of Charpy impact energy $A_{\mathrm{k}}$ versus plate thickness for steel plate at $20{ }^{\circ} \mathrm{C}$ are given in
Fig. 7a. It can be seen that as the plate thickness increases from 60 to $165 \mathrm{~mm}$, the transverse and through-thickness $A_{\mathrm{k}}$ values reduce by almost $11 \%$ and $80 \%$, respectively.

Curves for the $60 \mathrm{~mm}$ plate are shown in Fig. 7b. As the temperature decreases, the transverse $A_{\mathrm{k}}$ values drop quickly by nearly $60 \%$ while the throughthickness $A_{\mathrm{k}}$ values of the base metal and its HAZ reduce by more than $80 \%$.

Overall, the impact toughness along the transverse direction is obviously superior to that along the through-thickness direction, and the throughthickness impact energy values are extremely low. Compared with the base metal, the through-thickness $A_{\mathrm{k}}$ values of its HAZ are lower for each plate thickness. Chinese codes (CISA, 2006; 2009b) stipulate that the transverse $A_{\mathrm{k}}$ value should be $34 \mathrm{~J}$ at least for Q345 steel at the temperature points 20, 0, -20, and $-40{ }^{\circ} \mathrm{C}$. The results in this study show the bad through-thickness impact toughness of the thick plates. Note that the decline amplitudes of transverse $A_{\mathrm{k}}$ values are apparently less than the 


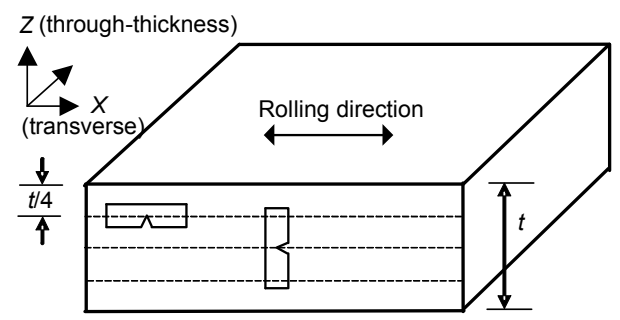

(a)

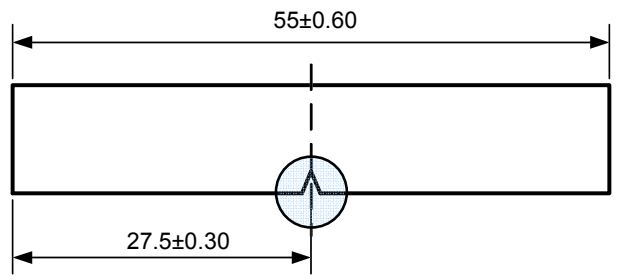

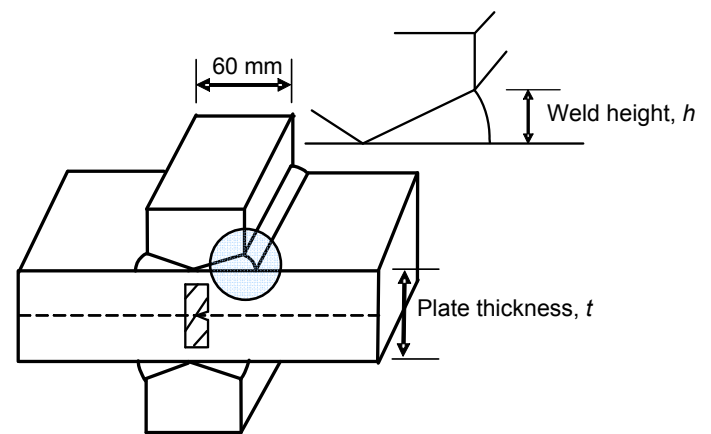

(b)

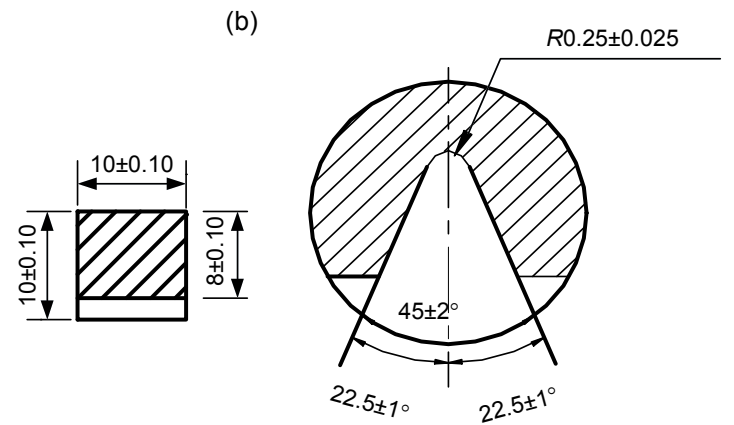

(c)

Fig. 6 Sampling location and physical dimension of Charpy V-Notch impact specimens (unit: $\mathrm{mm}$ ): (a) base metal specimens $(t=60,80,100,120,165)$; (b) HAZ specimen $(h=21)$; (c) standard Charpy V-Notch impact specimens

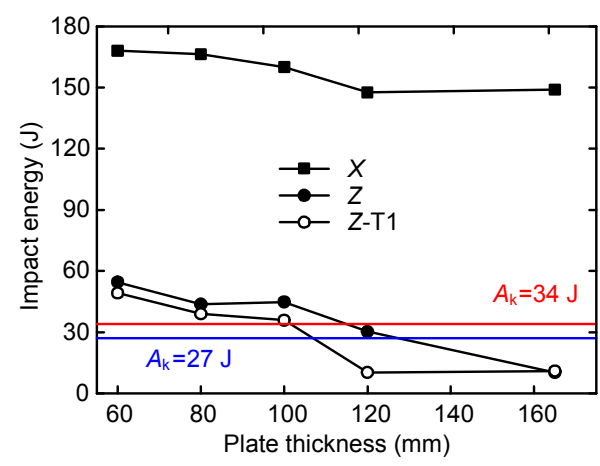

(a)

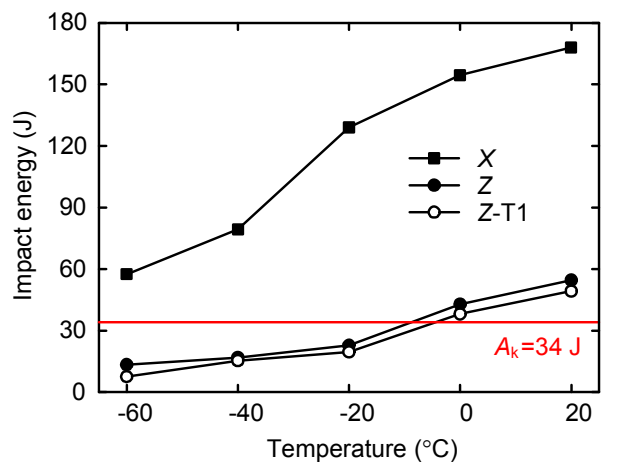

(b)

Fig. 7 Charpy impact energy versus the plate thickness at $20{ }^{\circ} \mathrm{C}$ (a) versus temperature with the plate thickness of $60 \mathrm{~mm}(\mathrm{~b})$ through-thickness values, which is consistent with the results of uniaxial tensile tests.

Ductile-brittle transition temperature is an important index for evaluating material brittleness at low temperatures, and it is commonly considered as the important criterion for preventing brittle fracture failure in engineering practice. The typical curve of Charpy impact energy versus temperature is S-shaped, comprising three regions: the transition region, and the upper and lower shelves. Then, the ductile-brittle transition temperature can be obtained by an S-shaped curve fitting.

Various test results have shown that the Boltzmann function can describe the relationship between Charpy impact energy and temperature (Wang et al., 2007). Therefore, the average Charpy impact energy $A_{\mathrm{k}}$ values from Charpy impact tests were regressed according to Eq. (3) using the Boltzmann function,

$$
A_{\mathrm{k}}(T)=\frac{A_{1}-A_{2}}{1+\exp \left[\left(T-T_{\mathrm{t}}\right) / T_{\mathrm{r}}\right]}+A_{2},
$$

where $A_{1}, A_{2}, T_{\mathrm{t}}$, and $T_{\mathrm{r}}$ are the curve-fitting parameters; $A_{\mathrm{k}}(T)$ is the Charpy impact energy at temperature 
$T ; A_{1}$ and $A_{2}$ are the lower and upper shelf energy, respectively; $T_{\mathrm{t}}$ is the ductile-brittle transition temperature; and $T_{\mathrm{r}}$ is the temperature range of the ductile-brittle transition region.

The Charpy temperature transition curves for the $60 \mathrm{~mm}$ plate are shown in Fig. 8, and the curve-fitting parameters in Eq. (3) obtained by the data regression of the Charpy impact tests are also indicated in Fig. 8. The ductile-brittle transition temperatures of transverse and through-thickness specimens from the base metal are -27.6 and $-6.6{ }^{\circ} \mathrm{C}$, respectively, indicating a better impact toughness along the rolling direction than that along the through-thickness direction. The through-thickness ductile-brittle transition temperature of the $\mathrm{HAZ}$ is $-5.76^{\circ} \mathrm{C}$, a little higher than that of the base metal, and it means HAZ is more likely to suffer brittle fracture at low temperatures.

\subsection{Scanning electron microscope images of fractured surfaces of the Charpy impact specimen}

SEM images of fractured surfaces of Charpy V-Notch impact specimens are illustrated in Fig. 9. The scanning location was close to the center of the fracture surface.

The fractograph of specimens for the $60 \mathrm{~mm}$ plate at $20^{\circ} \mathrm{C}$ (Fig. 9a), indicates that typical dimples and fibrous zones can be found in both transverse and through-thickness specimens from the base metal, while more cleavage planes and river patterns can be seen in the fracture surface of through-thickness specimens from HAZ but less dimples. This may be adversely influenced by the welding heat input, making the material become more brittle.

As shown in Fig. 9b, the images obtained at the fractured surface indicate that as the temperature decreases from 20 to $-60{ }^{\circ} \mathrm{C}$, the brittle fracture characteristics with cleavage stages and river patterns become more obvious. The microscopic features varying with temperature are consistent with the decrease of the macro impact energy values for the $60 \mathrm{~mm}$ plate from the HAZ.

The fractograph of through-thickness specimens from the base metal with different plate thicknesses $(60,120,165 \mathrm{~mm})$ at $20{ }^{\circ} \mathrm{C}$ is shown in Fig. 9c. Compared with the fractured surface of the $60 \mathrm{~mm}$

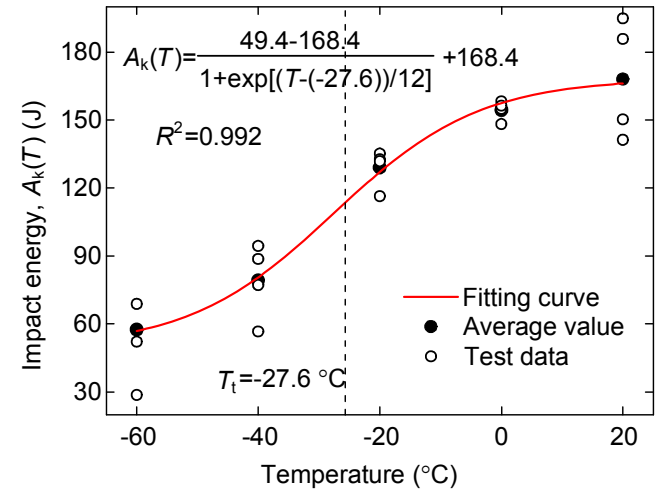

(a)

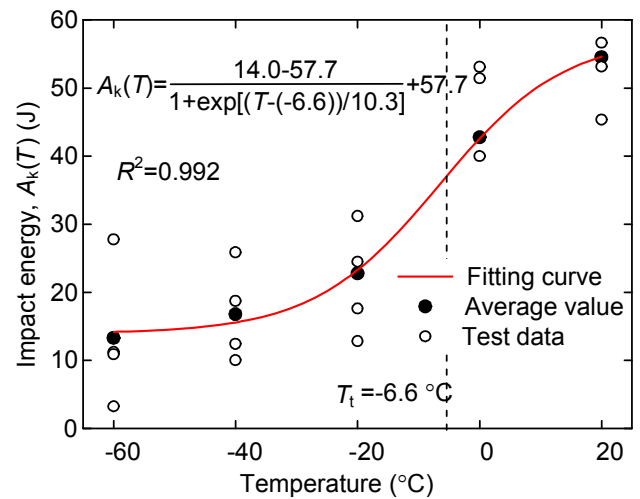

(b)

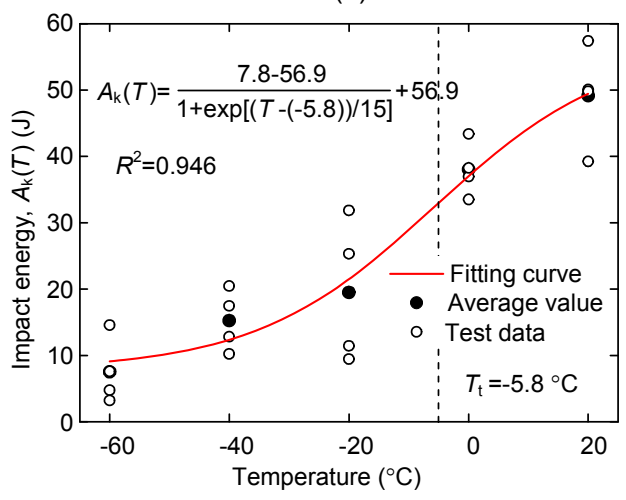

(c)

Fig. 8 Charpy temperature transition curves for the $60 \mathrm{~mm}$ plate: (a) transverse specimen from base metal $(X)$; (b) through-thickness specimen from base metal (Z); (c) through-thickness specimen from $\mathrm{HAZ}$ (Z-T1)

plate, that of the $120 \mathrm{~mm}$ plate exhibits more brittle characteristics with more cleavage stages and river patterns and that of the $165 \mathrm{~mm}$ plate has more cavities and defects. This also agrees well with the conclusions obtained by analyzing test data, and also indicates the large scatter of through-thickness mechanical properties in uniaxial tensile tests. 
(a)
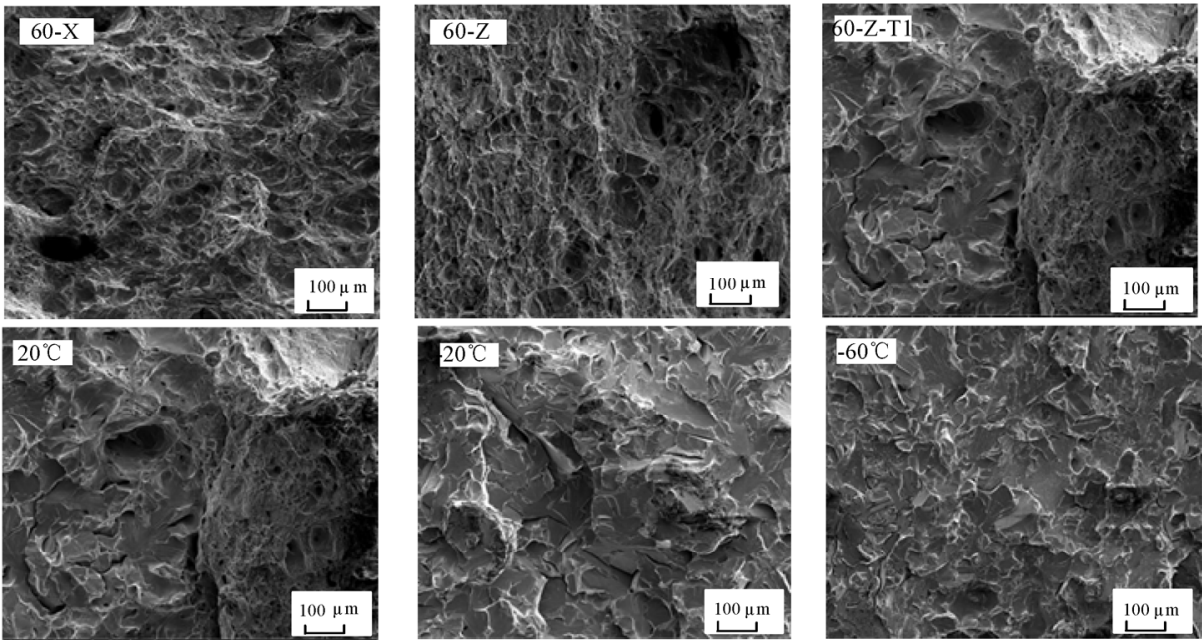

(b)

(c)
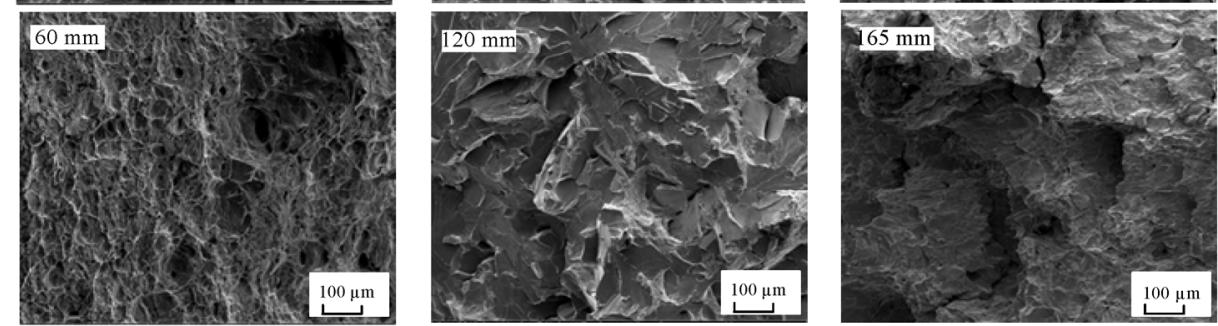

Fig. 9 SEM for fractured surfaces of Charpy impact specimen: (a) of the $60 \mathrm{~mm}$ plate at $20{ }^{\circ} \mathrm{C}$; (b) of fractured through-thickness specimen from $\mathrm{HAZ}(h=21 \mathrm{~mm})$ of the $60 \mathrm{~mm}$ plate; (c) of the fractured through-thickness specimen at $20{ }^{\circ} \mathrm{C}$

\section{Three-point bending tests}

\subsection{Three-point bending specimens}

Further study has been conducted employing TPB tests, as the fracture toughness index can evaluate the fracture resistant ability of materials quantitatively. The TPB specimens sampled from the base material and its HAZ influenced by the cross type butt weld are illustrated in Figs. 10a and 10b. The physical dimensions of the TPB specimen shown in Fig. 10c were in line with the standard GB/T 21143-2007 (CISA, 2008b). The thickness $B$, width $W$, and the distance of the two bearing points $S$ are 10, 20, and 80 $\mathrm{mm}$, respectively. The edge crack of the TPB specimen was fabricated by the method of wire cutting and fatigue pre-crack with the length of $3 \mathrm{~mm}$. The transverse crack direction is along the rolling direction of thick plates, and the through-thickness crack direction is perpendicular to the rolling direction. The test setup is illustrated in Fig. 10c.

\subsection{Experimental results and discussion}

The fracture toughness (critical values of CTOD) at temperatures from 20 to $-60{ }^{\circ} \mathrm{C}$ for Q345B steel (a)

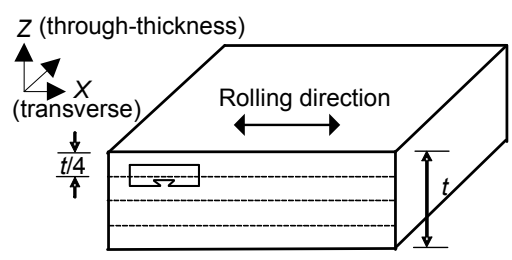

(b)

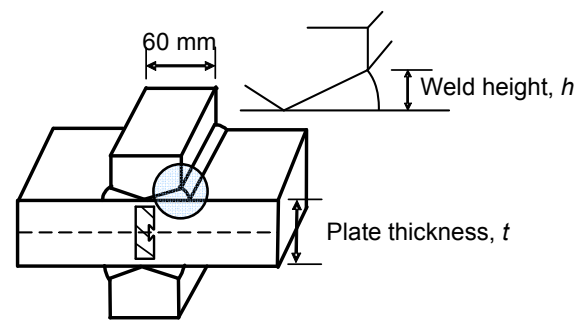

Loading punching

(c)

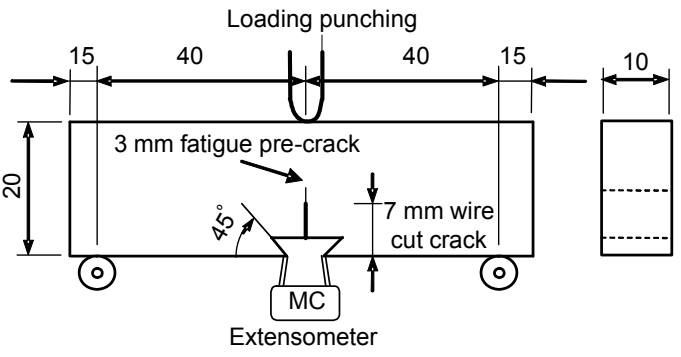

Fig. 10 Sampling location and physical dimension of TPB specimens (unit: $\mathbf{m m}$ ): (a) base metal specimens $(t=60,80$, 100, 120, 165); (b) HAZ specimens $(h=21,30,39,48)$; (c) TPB specimens and test setup 
of $60 \mathrm{~mm}$ plate and its HAZ were determined by TPB tests. Those tests were also extended for the steel plate with thicknesses from 80 to $165 \mathrm{~mm}$ at $20{ }^{\circ} \mathrm{C}$. The groupings of TPB test specimens are given in Table 2 , and three replicated TPB specimens were prepared for each condition point.

The displacement $V$ and load $P$ were measured with an extensometer and force sensor, respectively. The $V$ values denote the crack tip opening displacement, and $P$ values indicate the load exerted at the mid-span of the TPB specimen. According to the standard GB/T 21143-2007 (CISA, 2008b), the critical values of CTOD can be calculated by

$$
\delta=\frac{K_{\mathrm{I}}^{2}\left(1-v^{2}\right)}{2 f_{\mathrm{y}} E}+\frac{0.4\left(W-a_{0}\right) V_{\mathrm{p}}}{0.6 a_{0}+0.4 W},
$$

where $K_{\mathrm{I}}=g\left(a_{0} / W\right) P /\left(B W^{1 / 2}\right) ; B$ and $W$ denote the width and thickness of the TPB specimen, respectively; the value of $V_{\mathrm{p}}$ is obtained by the $P-V$ curves; and Poisson's ratio $v$ and the elastic modulus $E$ are taken as 0.3 and $2.06 \times 10^{5} \mathrm{MPa}$, respectively. For the TPB specimen with $0.45 \leq a_{0} / W \leq 0.57$, the stress intensity factor coefficient $g\left(a_{0} / W\right)$ can be determined by

$$
\begin{aligned}
g\left(a_{0} / W\right)= & \left\{3 ( a _ { 0 } / W ) ^ { 1 / 2 } \left[1.99-\left(a_{0} / W\right)\left(1-a_{0} / W\right)\right.\right. \\
& \left.\left.\times\left(2.15-3.93 a_{0} / W\right)+2.7 a_{0}^{2} / W^{2}\right]\right\} \\
& /\left[2\left(1+2 a_{0} / W\right)\left(1-a_{0} / W\right)^{3 / 2}\right] .
\end{aligned}
$$

While the front line of the fatigue pre-crack is curved, as shown in Fig. 11, nine measurements of crack length were conducted at positions across the specimen thickness. Then, the initial crack length was calculated by Eq. (6) and should also meet Eq. (7).

$$
\begin{aligned}
& a_{0}=\frac{1}{8}\left[\left(\frac{a_{1}+a_{9}}{2}\right)+\sum_{j=2}^{j=8} a_{j}\right], \\
& \left|a_{i}-a_{0}\right| \leq 0.1 a_{0}, \forall i=2,3, \ldots, 8 .
\end{aligned}
$$

In this study, the CTOD value $\delta_{\mathrm{m}}$ corresponding to the maximum load was considered as the critical value of CTOD. The average $\delta_{\mathrm{m}}$ values of test data for thick plates and HAZ at the varied location, temperature, and plate thickness are shown in Fig. 12. As the weld size increases, the average values $\delta_{\mathrm{m}}$ at $20{ }^{\circ} \mathrm{C}$

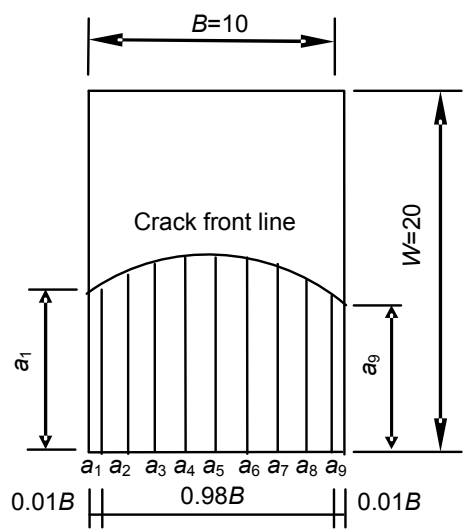

Fig. 11 Initial crack length measurement of fractured surface for the TPB specimen (unit: $\mathrm{mm}$ )

decrease for the plate thicknesses of 60,120 , and $165 \mathrm{~mm}$. While the temperature changes from 20 to $-60{ }^{\circ} \mathrm{C}$, the transverse values $\delta_{\mathrm{m}}$ from base material of the $60 \mathrm{~mm}$ plate reduce by more than $30 \%$ and through-thickness values $\delta_{\mathrm{m}}$ of its $\mathrm{HAZ}(h=21 \mathrm{~mm})$ reduce by nearly $60 \%$. As the plate thickness increases from 60 to $165 \mathrm{~mm}$, both the transverse and though-thickness values $\delta_{\mathrm{m}}$ experience a rapid drop by almost $40 \%$ and $50 \%$, respectively. On the whole, the transverse average values $\delta_{\mathrm{m}}$ are much higher than the through-thickness average values $\delta_{\mathrm{m}}$, and the even lower $\delta_{\mathrm{m}}$ values of the HAZ show worse throughthickness fracture toughness than that of the base metal.

\subsection{Scanning electron microscope images of three-point bending fracture surface}

SEM images of the fractured TPB specimens for the $60 \mathrm{~mm}$ plate are shown in Fig. 13. The scanning location was near the center of the fracture surface. As shown in Fig. 13a, the fractograph of the transverse specimen exhibits typical dimples. Due to the adverse effect of welding heat input, the fractured surface of the through-thickness specimen from HAZ $(h=21 \mathrm{~mm})$ has the junctional region of dimples and cleavage planes, while that from HAZ $(h=39 \mathrm{~mm})$ shows obvious brittle features with more cleavages. The microscopic characteristics varying within the sampling location agree well with the variation of the macro toughness indices $\delta_{\mathrm{m}}$. As the temperature decreases, dimples of fractured surfaces become fewer, and the cleavage planes and stages become more obvious (Fig. 13b), indicating that the brittle fracture feature is more likely to occur at low temperatures, which is consistent with the data analysis of TPB tests. 


\section{Conclusions}

1. For the $60 \mathrm{~mm}$ thick plate, as the temperature decreases from 20 to $-60{ }^{\circ} \mathrm{C}$, the yield and ultimate tensile strengths along the transverse and throughthickness directions increase, and the transverse and through-thickness ductility indices increase. As the plate thickness increases, the strength and ductility indices along both the transverse and throughthickness directions decrease, and, especially for those of plates from 100 to $165 \mathrm{~mm}$, experience a drastic drop. The through-thickness strength and ductility are also reduced by increasing welding heat input.

2. With the increase of plate thickness, both transverse and through-thickness Charpy impact toughness values decrease, which is in accordance with the results of SEM images. For the $60 \mathrm{~mm}$ plate, as the temperature falls from 20 to $-60{ }^{\circ} \mathrm{C}$, the through-thickness Charpy impact toughness drops more rapidly than that along the transverse direction. The through-thickness material has a lower transition temperature than the transverse material, while that of
HAZ is the lowest. In addition, the HAZ has lower through-thickness Charpy impact energy than the base material.

3. Both the transverse and through-thickness fracture toughness values (the critical values of CTOD) $\delta_{\mathrm{m}}$ of the $60 \mathrm{~mm}$ plate decrease with the decline of temperature. As the plate thickness increases, the transverse and through-thickness fracture toughness decrease. Besides, the increased weld sizes also reduce the through-thickness fracture toughness, agreeing well with the analytical results of the SEM images.

4. Generally, the yield strength, ultimate tensile strength, ductility index, Charpy impact toughness and fracture toughness along the transverse direction are superior to those along the through-thickness direction. The adverse effect of welding heat input reduces these through-thickness mechanical and toughness indices to some extent, indicating the deteriorated through-thickness properties of HAZ. Moreover, the through-thickness properties seem to be more susceptible to variation in temperature and plate thickness than the transverse properties.
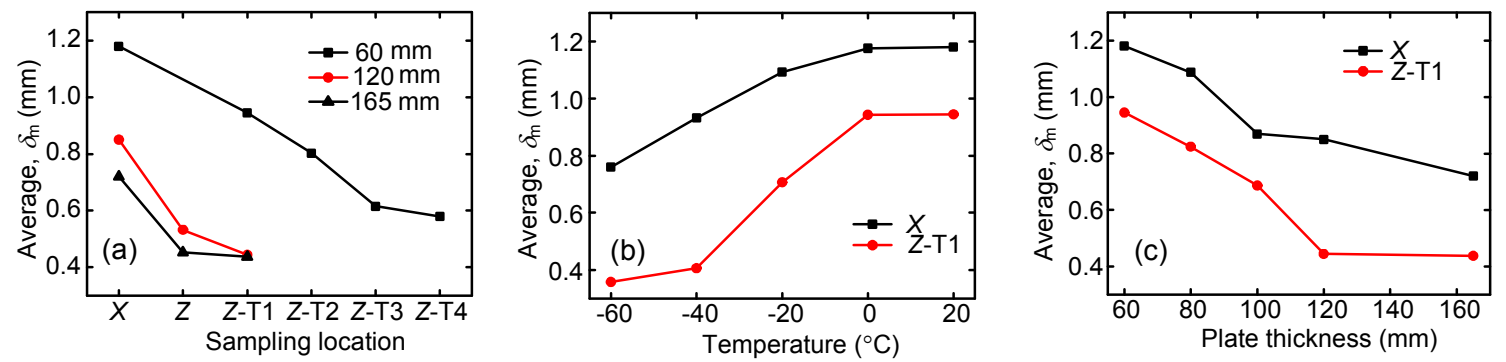

Fig. 12 CTOD values $\delta_{\mathrm{m}}$ versus different sampling locations, temperatures, and plate thicknesses: (a) different locations at $20{ }^{\circ} \mathrm{C}$; (b) different temperatures for the $60 \mathrm{~mm}$ plate; (c) different plate thicknesses at $20{ }^{\circ} \mathrm{C}$

(a)

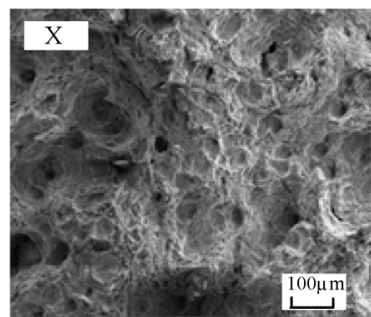

(b)

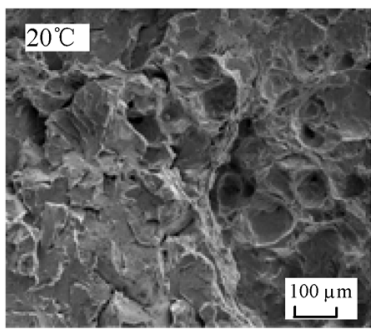

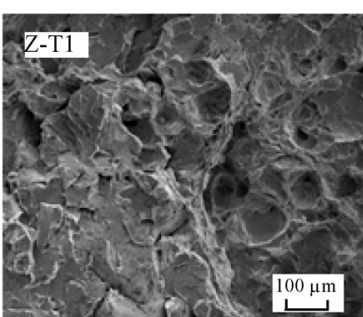

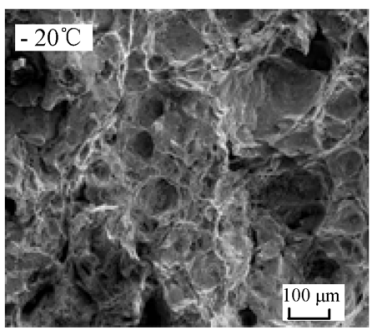

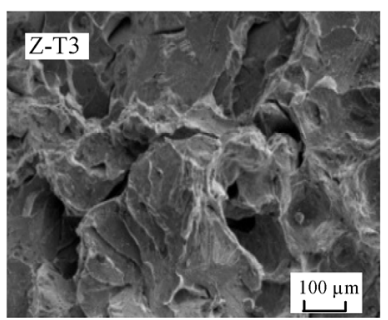

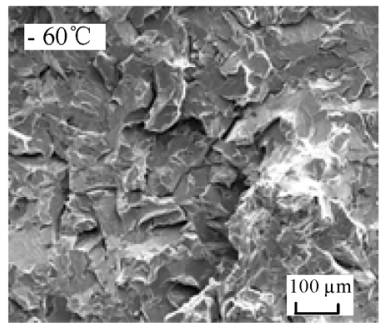

Fig. 13 SEM images for fractured surfaces of TPB specimen: (a) fractured specimen of the $60 \mathrm{~mm}$ plate at $20{ }^{\circ} \mathrm{C}$; (b) fractured through-thickness specimen from $\mathrm{HAZ}(h=21 \mathrm{~mm})$ of the $60 \mathrm{~mm}$ plate 


\section{References}

Barsom, J.M., Korvink, S.A., 1998. Through-thickness properties of structural steels. Journal of Structural Engineering, 124(7):727-735. [doi:10.1061/(ASCE)07339445(1998)124:7(727)]

Chai, C., 2004. Application of steel thick plates to steel work constructions and selection of their character. Steel Construction, 19(5):47-53 (in Chinese).

Chen, L.R., 2007. The characteristics of structural steel for the main building in new location of China Central Television Station. Steel Construction, 22(1):1-4 (in Chinese).

CISA (China Iron and Steel Association), 2006. Steel Plates for Building Structure, GB/T 19879-2005. National Standards of People's Republic of China (in Chinese).

CISA (China Iron and Steel Association), 2007. Metallic Materials - Tensile Testing at Low Temperature, GB/T 13239-2006. National Standards of People's Republic of China (in Chinese).

CISA (China Iron and Steel Association), 2008a. Metallic Materials - Charpy Pendulum Impact Test Method, GB/T 229-2007. National Standards of People's Republic of China (in Chinese).

CISA (China Iron and Steel Association), 2008b. Metallic Materials-Unified Method of Test for Determination of Quasistatic Fracture Toughness, GB/T 21143-2007. National Standards of People's Republic of China (in Chinese).

CISA (China Iron and Steel Association), 2009a. Structural Steel for Bridge, GB/T 714-2008. National Standards of People's Republic of China (in Chinese).

CISA (China Iron and Steel Association), 2009b. High Strength Low Alloy Structure Steels, GB/T 1591-2008. National Standards of People's Republic of China (in Chinese).

CISA (China Iron and Steel Association), 2011. Steel Plates with Through-thickness Characteristics, GB/T 5313-2010. National Standards of People's Republic of China (in Chinese).

Gao, S.D., Li, J.L., Qiu, D.L., et al., 2008. Study on the welding technique of the Q460E-Z35 extra thick steel plate of steel structure for Beijing National Stadium. Industrial Construction, 38(7):85-88 (in Chinese).

Kuwamura, H., Iyama, J., Matsui, K., 2003. Effects of material toughness and plate thickness on brittle of steel members. Journal of Structural Engineering, 129(11):1475-1483. [doi:10.1061/(ASCE)0733-9445(2003)129:11(1475)]

Ren, D.L., Xiao, F.R., Tian, P., et al., 2009. Effects of welding wire composition and welding process on the weld metal toughness of submerged arc welded pipeline steel. International Journal of Minerals, Metallurgy and Materials, 16(1):65-70. [doi:10.1016/S1674-4799(09)60011-X]

SBMI (State Bureau of Metallurgical Industry), 2002. Metallic Materials-Tensile Testing at Ambient Temperature, GB 228-2002. National Standards of People's Republic of China (in Chinese).

Wang, Y.Q., Xi, W., Shi, Y.J., 2007. Experimental study of the impact toughness of rail steel at low temperature. Journal of Tsinghua University (Science and Technology), 47(9): 1414-1417 (in Chinese).

Wang, Y.Q., Zhou, H., Shi, Y.J., et al., 2010. A research review on mechanism and prevention of lamellar tearing in thick plate of steel structures. Progress in Steel Building Structures, 12(5):26-34 (in Chinese).

Wang, Y.Q., Zhou, H., Shi, Y.J., et al., 2012. Mechanical properties and fracture toughness of rail steels and thermite welds at low temperature. International Journal of Minerals, Metallurgy and Materials, 19(5):409-419. [doi:10.1007/s12613-012-0572-8]

Wang, Y.Q., Liu, X.Y., Hu, Z.W., et al., 2013. Experimental study on mechanical properties and fracture toughness of structural thick plate and its butt weld along thickness and at low temperatures. Fatigue \& Fracture of Engineering Materials and Structures, 36(12):1258-1273. [doi:10. 1111/ffe.12062]

Wu, Y.M., Wang, Y.Q., Shi, Y.J., 2004. Effects of low temperature on properties of structures steels. Journal of University of Science and Technology Beijing, 11(5):442-448.

Zhang, D.M., 2006. Test study of through-thickness property of $14 \mathrm{MnNbq}$ steel plate. Bridge Construction, (S1): 140-142 (in Chinese).

Zhao, Y.L., Shi, J., Cao, W.Q., et al., 2010. Effect of direct quenching on microstructure and mechanical properties of medium-carbon Nb-bearing steel. Journal of Zhejiang University-SCIENCE A (Applied Physics \& Engineering), 11(10):776-781. [doi:10.1631/jzus.A1000147]

\section{中文概要}

题 目: 低温条件下钢结构厚板及其热影响区的 $Z$ 向性能 试验研究

目 的：系统研究钢结构厚板在常温和低温条件下的 $Z$ 向 性能, 并为其工程应用和评价指标的制定提供基 础数据。

方 法: 在常温和低温条件下, 分别通过单轴静力拉伸试 验、夏比 $\mathrm{V}$ 型缺口冲击韧性试验和三点弯曲试验, 研究钢结构厚板钢材及其热影响区的 $Z$ 向和沿钢 板轧制方向的力学性能指标、冲击㓞性和断裂韧 性随温度和钢板厚度变化的规律; 并通过扫描电 镜微观图像分析冲击试验和断裂试验的断口随 温度和钢板厚度的变化。

结 论: 1 . 钢结构厚板的 $Z$ 向性能要低于沿钢板轧制方向 的性能, 包括屈服强度、抗拉强度、延性指标、 冲击韧性和断裂㓞性; 2 . 焊接热输入会降低钢结 构厚板热影响区母材 $Z$ 向的力学和㓞性指标; 3. 相比沿轧制方向的性能, 钢结构厚板的 $Z$ 向性 能对温度和厚度的变化更敏感。

关键词: 钢结构厚板; $Z$ 向性能; 力学性能; 冲击韧性; 断裂㓞性; 低温环境 